\title{
StuA is required for cell pattern formation in Aspergillus
}

\author{
Karen Y. Miller, Jianguo Wu, and Bruce L. Miller ${ }^{1}$ \\ Department of Bacteriology and Biochemistry, University of Idaho, Moscow, Idaho 83843 USA
}

The stunted (stuA) gene product is required for the orderly differentiation and spatial organization of cell types of the Aspergillus nidulans conidiophore. Expression of the stuA gene is complex. Two transcripts, stuAa and $\operatorname{stuA\beta }$, are initiated from separate promoters. Transcription of both RNAs increases $\sim 50$-fold during the establishment of developmental competence. Induction-dependent transcriptional and post-transcriptional regulatory mechanisms further enhance expression 15-fold. Consistent with the latter observation, both transcripts have structural features characteristic of RNAs subject to translational control. Conidiophore morphogenesis requires regulatory interactions between the products of the $s t u A$, bristle (brlA), and abacus $(a b a A)$ genes. Enhanced stunted expression is cell type specific and dependent on a functional BrlA protein. StuA affects the spatial localization of AbaA by acting directly, or indirectly, to repress abaA expression.

[Key Words: Aspergillus nidulans; conidiation; spatial regulation; pattern formation]

Received January 1, 1992; revised version accepted July 1, 1992.

The asexual reproductive cycle (conidiation) of the filamentous ascomycete Aspergillus nidulans is characterized by a coordinated temporal and spatial pattern of cell differentiation (for review, see Miller 1990; Timberlake 1990). The mature conidiophore is a multicellular structure consisting of foot cell, aerial hypha, terminal vesicle, and single tiers of metulae and phialides. The latter two cell types are uninucleate cells with the phialide undergoing repeated mitotic divisions to yield chains of conidia (Mims et al. 1988; Sewall et al. 1990). The genetic hierarchy controlling conidiation can be divided into preinduction and postinduction loci /Clutterbuck 1969, 1977; Axelrod et al. 1973; Pastushok and Axelrod 1976; Champe et al. 1981; Yager et al. 1982; Butnik et al. 1984). After conidium germination, preinduction loci determine biochemical events that allow the vegetative mycelia to acquire reproductive competence. Phenomena associated with competence can be experimentally separated from those of induction. Mycelia maintained as submerged cultures remain in a competent but undifferentiated state. Synchronous induction, by exposure to an air interface, results in sequential activation of $\sim 1200$ stage-specific RNAs (Timberlake 1980).

Correct cell pattern formation requires the functions of at least five genes: abacus $(a b a A)$; bristle $(b r l A)$; medusa (medA); stunted (stuA); and wet-white conidia (wetA) (Clutterbuck 1969, 1977; Martinelli and Clutterbuck 1971). Epistatic relationships suggest that these postinduction loci define two separate genetic pathways with some interaction, or overlap, in function (Martinelli 1979). The BRISTLE group of genes $(b r l A \rightarrow a b a A$ $\rightarrow$ wet $A$ ) define a linear path of differentiation that cul-

${ }^{1}$ Corresponding author. minates in the formation of the conidium. Null mutations in members of this group are aconidial, with development being blocked at conidiophore vesicle, phialide, and mature conidium formation, respectively /Clutterbuck 1969). Molecular analysis has demonstrated a linearly dependent regulatory relationship for members of the BRISTLE group (Boylan et al. 1987; Adams et al. 1988; Mirabito et al. 1989; Marshall and Timberlake 1991). Ectopic expression of the transcriptional activator BrlA resulted in the cessation of vegetative growth. Hyphal tips acquired phialide-like features and produced conidia (Adams et al. 1988). Therefore, BrlA expression is necessary and sufficient to direct the linear transition from vegetative hyphae to conidia. Normal patterns of cell differentiation, however, require additional regulatory phenomena (Clutterbuck 1977; Martinelli 1979).

Genes of the STUNTED group (stuAA $\rightarrow$ medA) have been classified as developmental modifiers. They affect patterns of cell differentiation and the spatial organization of the conidiophore (Clutterbuck 1969; Martinelli 1979; Miller et al. 1991). stuA null mutants have greatly shortened conidiophores and lack normal metulae and phialides. Abnormal conidia frequently differentiate directly from buds formed on the conidiophore vesicle. medA mutations result in reiterated metulae and secondary conidiophore structures. Both $\operatorname{stu} A$ and medA mutants are also self-sterile, failing to form sexual reproductive structures (cleistothecia). Previously, we have described the physical isolation of the $s t u A$ gene (Miller et al. 1991) and have recently cloned the medA gene (K. Miller and B. Miller, in prep.). Although StuA is not required for vegetative growth, we found that $s t u A$ was transcriptionally activated during the acquisition of developmental competence. Transcriptional activation 
was induction independent and under the control of unknown genetic loci (Miller et al. 1991).

Here, we report the nucleotide sequence and transcriptional organization of the $s t u A$ gene. Structural features of the two alternate $s t u A$ mRNAs and the temporal and spatial expression of a $s t u A(\mathrm{p} / 1):: 1 a c Z$ reporter gene suggest that induction-dependent, cell-type-specific expression is subject to both transcriptional and translational regulatory mechanisms that require a functional BrlA protein. Furthermore, we have observed that the ability of BrlA to activate transcription of $a b a A$ is apparently modulated by the transient and spatially restricted repression of $a b a A$ expression by StuA. Therefore, conidiophore morphogenesis in $A$. nidulans requires complex interactions between functions of $\mathrm{AbaA}, \mathrm{BrlA}$, and StuA.

\section{Results}

Two stuA mRNAs are produced by the use of alternate promoters and RNA splicing patterns

The structural features of the stuA gene are summarized in Figure 1 and in the DNA sequence shown in Figure 2. Transcriptional organization was determined by $\mathrm{Sl}$ nuclease protection, primer extension, and DNA sequence analysis of PCR-generated cDNA clones, as described in Materials and methods. Two mRNAs, designated stuAa and $s t u A \beta$, are similar in size 13335 and 3470 nucleotides, respectively| but are generated by alternate processing of RNAs initiated from different transcriptional start sites. Three introns common to both stuA $\alpha$ and stuA $\beta$ transcripts are small $(45,47$, and 46 nucleotides $)$ and typical of fungal genes. The first intron of the stuA $\beta$ transcript, however, is 497 nucleotides in size and is the largest intron that has been reported for a fungal gene. Transcription of stuA $\alpha$ is initiated 635 bp downstream of the stuA $\beta$ RNA start sites, within DNA sequences specifying this large intron.

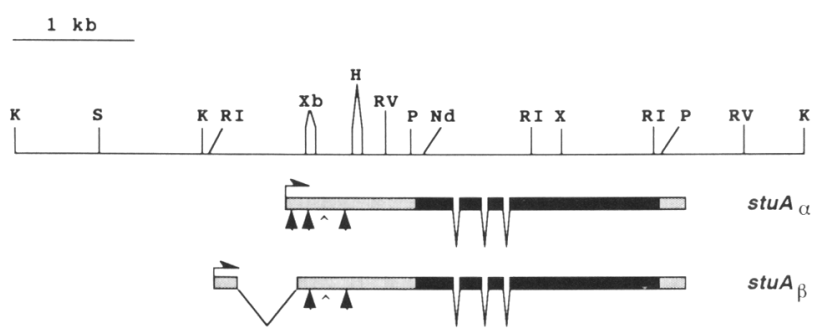

Figure 1. Structure of the stuA gene. Schematic drawing of the transcriptional unit and DNA sequences required for complementation of both asexual and sexual reproductive deficiencies of a $\operatorname{stuA}$ null mutant. Arrows indicate transcriptional initiation sites and the direction of transcription of the $\alpha$ and $\beta$ transcripts. Stippled boxes represent transcribed, nontranslated mRNA sequences; solid boxes indicate the major stuA ORF that begins with an AUG codon. Mini-ORFs found within nontranslated leader sequences are indicated by solid triangles and are designated mORF 1-3 (from left to right). mORF 1 is unique to the $\alpha$ transcript. A caret $(\lambda$ indicates the position of an additional AUG codon found in the nontranslated leader. $(\mathrm{H}) \mathrm{Hin}$ dIII; (K) KpnI; (Nd) NdeI; (P) PstI; (R1) EcoRI; (RV) EcoRV; (S) SalI; $(\mathrm{X})$ XhoI; (Xb) Xbal.
stuA $\alpha$ and stuA $\beta$ mRNAs possess long nontranslated leaders with multiple mini-ORFs

The first AUG codon of the stuA open reading frame (ORF) is located 1088 nucleotides downstream of the $\alpha$ cap site and 1221 nucleotides downstream of the $\beta$ cap site (Figs. 1 and 2). These leader sequences are the longest that have been described for the filamentous fungi. Both $\alpha$ and $\beta$ leaders have two common AUG-initiated mini-ORFs (mORFs 2 and 3 ) of 8 and 3 amino acids, respectively. There is also a common AUG codon followed immediately by a stop codon. A third mini-ORF (mORF 1) of 24 amino acids is found at the extreme $5^{\prime}$ end of the $\alpha$ leader, in sequences unique to this transcript (Figs. 1 and 2). The stop codon of mORF 1 is also the $3^{\prime}$ splice junction of the large stuA $\beta$ intron. Therefore, processing of the $\beta$ precursor RNA removes mORF 1. Long nontranslated leaders containing mini-ORFs are characteristic of mRNAs from a number of genes in which expression has been demonstrated to be under translational control (Hinnebusch 1984; Thireos et al. 1984; Werner et al. 1987; Garret et al. 1989).

\section{stuA gene encodes a 63.5-kD polypeptide}

Both the $s t u A \alpha$ and $s t u A \beta$ mRNAs potentially encode the same 590 -amino-acid, $63.5-\mathrm{kD}$ polypeptide. StuA has a predicted pI of 8.48 and consists of $12 \%$ serine, $11 \%$ proline, and $11 \%$ basic amino acids (Fig. 2). The majority of the basic residues are found in two domains. An amino-terminal domain (residues 148-215) consists of $24 \%$ basic amino acids and is largely defined by exon 3 of the $\alpha$ RNA (exon 4 of the $\beta$ transcript). A carboxy-terminal domain (residues 545-570) contains two clusters of amino acids, KRMR and KRRK, separated by an 18-residue spacer. This 26-amino-acid domain closely resembles the bipartite nuclear targeting signal described for mammalian nucleoplasmin and a number of mammalian transcription factors (Robbins et al. 1991). Secondary structure predictions (Garnier et al. 1978; Gascuel and Golmard 1988) suggest that StuA consists almost entirely of extended or random coil conformation. The limited $\alpha$-helical structure consists of two helices (residues 134-150 and 205-217) that lie on either side of the amino-terminal basic domain and a third helix /residues 180-187) that lies within this domain. There are two Pro/Gln-rich regions that could function as transcriptional activation domains (Mitchell and Tjian 1989). One region (residues $39-129$ ) is $23 \%$ proline, $10 \%$ glutamine, and $17.5 \%$ serine, whereas the second (residues 253-395) is $20 \%$ proline, $12 \%$ glutamine, and $16 \%$ serine. A search of the current nucleotide and protein data bases did not reveal any gene products with significant sequence similarities to StuA.

Maior changes in stuA RNA abundance are associated with acquisition of developmental competence rather than induction

The stuA $\alpha$ and stuA $\beta$ transcripts are barely detectable in mature conidia or in mycelia that are not developmen- 
Miller et al.

tally competent. A 50-fold increase in the relative abundance of both transcripts, however, coincides with the establishment of developmental competence (Miller et al. 1991). After induction, the relative abundance of the $\alpha$ and $\beta$ transcripts increased approximately fivefold and twofold, respectively (Fig. 3A). These increases occurred 5-7.5 hr postinduction, during conidiophore vesicle, metulae, and phialide differentiation. Semiquantitative

1

aaattattatttgtcctaatcagatcagtgtctagtgtttagtgtttagtgtttgcacatcgtggcggggctggtccttgcttcgtggcgacaatactg $101 \ldots$ ....

agcaatggagtatagtctgtgcacgtccgctgcaattttcatttaccggtaccgcgtctgaacgggtggacgtggattttgggattttgaattccegct 201 ..........

^ gggatgctgactccgaccatccataagacatä. . . . 301

TCTTAAAGAGCAGCGGCAGAGACAGTCAAGACTCAAGTCAGTCTGGCAGGAAATTGCCTTGCCTTGCCTTGCAGCTACATCCGTCTCAGACAGACTCAGG 401

ACGCAGAGCACGACACGTGCCTTTACAGACAAGACGAGCAAGACGACCAAAACGACCAAAACGACCAAGACGACCAAGACAGTGCTCAGTACATCGTAGg 501

taagtcaagggcgccggcgccagccttcagagttcatcccatccetcaacagcttccctcttaccttagcctgcgtttgctccagcctcceagcctcc 601


701

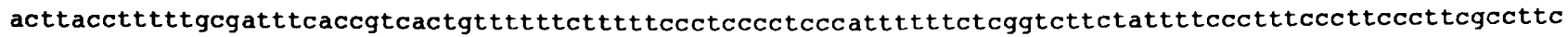
801 tccaccgacctcctccttctcctctccctctgctccgtcatccetttcgtttgacgtgacgccttttatacatattcgcgtcggttccgtctggtcttcg $>>$

tcgctcatccttttcgtcccttcaatgtgectgtacctttgcctgtgccegctacgactaatgacctcccaactcactcgtgctttgctcgetttctag 1001

ACTCGCCCGCTCAACGACCTGCTACGACCTGTTACGACTCTTGTACGAGCCTGATTTGAAATTCGCTGCAGCCCGCATACATATCATTGCCATTTCTGCC 1101 TCGCTCTAGACGCCGTCTGCTTCTCTGTCTGTCCAAGTCGGTTCCCCGCTCCGTCCTTCCAAGTTACGACCTGAAACGAGACCCATGATTCTGCGCTGCT 1201 GCCGCCGTTGACCTCCCGAACCATTTTGCCTCCGCCGCGGTCGATCCTTCGGATGTAGATAGTCTTCTCAACTGCAGCCCATTTCTCGACTCCGTTTGCC 1301

TGCAATCTAAAGCGCTGTTACGGGTTACGACGTTTCACGAAGCTTGCCACGATTGCTCTTCCTTGCATTTTCGTATTGCCTATTGGAGCCATTTTCTTT 1401 GCGTTATTGGATTTTGCAACCTGAACGACCTCTTTGCATATCTGCTGCGAAGCTTCTCCGTGTCCTCGACATCGCCTTTCCTATCTCATGAGTITCTGAA 1501

AACAGCACGCAAGACTTATTAAACGTTGGATCTTTTCGACTCCGACGTGCCCTCGCCTCGACTTTTTCTTCTCATTTCTTAGACCTGTTTTTCTCCGCCA 1601

ACCGAAAAGCTGGAGCTGCCGTCGATCTCCCAGGTCCACACCAGAGGTCCTGTTGATATCCCTTGGTATAATCACCACGCCGCGGAGCGACCTCTGTTGT 1701 CTGGTGACAGACTTCCGGCTCTAAGCATCCCGACGGCCTCGCAGCCGCCGACCTCGGGCCAGTCCTACCGGACTAGCTACGAAGACGCGCCGGCCTCCAA 1801 CCAGAGCAGCGCCAGAACCAGTCTGTCCGGGTCCGCGCCTGGCTACGAAGTTCGTAGCCCGCCGGCATCGTCTGCAGATATACCGGCTGGTGGCCAAGCA 1901 CGACTCTCGCTgGACTCTTCCGCCTCGCAGgAATACAGCATTCCGCAGAACCCAGTCACCGAGAGCTACTACCCCAACCAGACCCAG ATG GCC AGC

1995 $\begin{array}{lll}M & \mathrm{~A} & \mathrm{~S} \\ & & \end{array}$ ATG AAT CAA CCT CAA CCG TAC ATG GAT GTG CAT TCG CAT CTG TCG TCG GGA CAG ACA TAT GCG TCC CAC CCT GCA

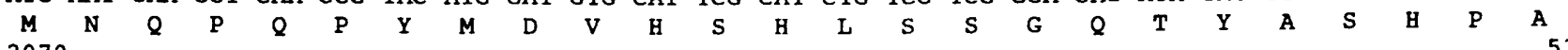
2070

ACT GCT GGA GCA TTG ACC CAT TAC CAG TAC CCG CAA CAA CCC CCT GTG TTA CAA CCG ACG TCC ACA TAC GGG CCG

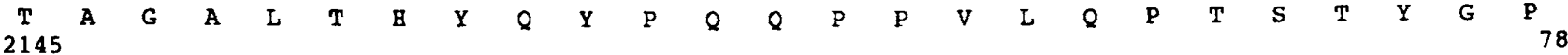
GCC AGC TCT TAC TCC CAG TAT CCT TAT CCC AAC AGT GTA GCA TCA TCT CAG TCT GTC CCG CCG CCG ACG ACG TCG

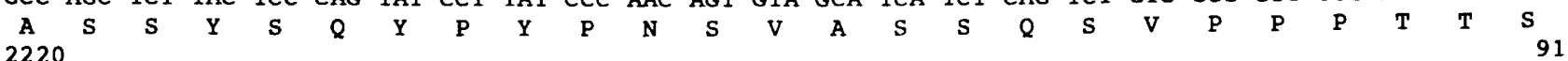
ATT AGC AGT CAA GTC CCT GCT CAA CTA CTG CCC TTA CCT G gtaagtacgcggacgcattgtcagcagtaagtactgacctcctag $\begin{array}{lllllllllllll}I & S & S & Q & V & P & A & Q & L & L & P & L & P\end{array}$ $2305 \quad 116$ TC ACC AAC CAC CCT GTT CCC ACC CAC GGA TAT GGA AAC AAC AGC GGA ACA CCA ATG CAA GGG TAT GTA TAC GAT


2379 T CCC ACT GGg CAG ATG GCG CCT CCC GGC GCT AAg CCT AGg GTT ACC GCG ACC CTG TGG GAA GAC GAA GGC AGT CTC

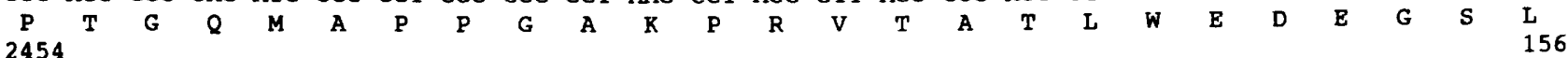
TGC TAC CAA GTG GAA GCC AAG GGT GTC TGC GTT GCT CGA AGA GAA G gtgagagactcggcacgtttgtggtagatctggactaa $\begin{array}{llllllllllllllll}C & Y & Q & V & E & A & R & G & V & C & V & A & R & R & E\end{array}$ 2538 ttttgtag AT AAT GGC ATG ATC AAC GGC ACC AAG CTG CTA AAC GTT GCG GGC ATG ACA CGA GGC CGA AGA GAC GGT



Figure 2. (See facing page for legend.) 
2615

201

ATC CTC AAG AGT GAA AAG GTC CGA AAT GTG GTA AAG ATT GGC CCG ATG CAT CTG AAg GGC GTT TG gtaagtctctctc

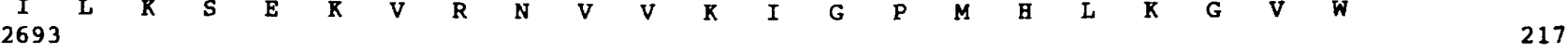
ccgtattttccataatatcgttaacceaagtag G ATT CCC TTT GAC CGC GCG CTG GAA TTC GCC AAC AAG GAA AAG ATC ACA

2775 $\begin{array}{lllllllllllllllll}I & P & F & D & R & A & L & E & F & A & N & K & E & K & I & T \\ 242\end{array}$

GAT CTG TTA TAC CCT TTG TTC GTT CAA CAC ATC AGC AAC CTG CTG TAC CAC CCG GCG AaC CAG AAT CAG AGg AAC $\begin{array}{lllllllllllllllllllllllllll}D & \text { L } & \text { L } & \text { Y } & \text { P } & \text { L } & \text { F } & \text { V } & \text { Q } & \text { B } & \text { I } & \text { S } & \text { N } & \text { L } & \text { L } & \text { Y } & \text { B } & \text { P } & \text { A } & \text { N } & Q & \text { Q } & \text { N } & R & \text { N }\end{array}$ 2850

ATG ACA GTG CCA GAT TCC AGA CGT CTT GAA GGC CCC CAA CCT GTT GTT CGC ACC CCT CAA GCA CAG CAA CCA CCC $\begin{array}{llllllllllllllllllllllllll}M & \text { T } & \text { V } & \text { P } & \text { D } & \text { S } & \text { R } & \text { R } & \text { L } & \text { E } & \text { G } & \text { P } & \text { Q } & \text { P } & \text { V } & \text { V } & \text { R } & \text { T } & \text { P } & \text { Q } & \text { A } & \text { Q } & \text { Q } & \text { P } & \text { P } \\ 2925 & & & & & & & & & & & & & & & & & & & \end{array}$ AGC CTA CAC CAC CAT TCT CTT CAG ACA CCC GTT CCT TCT CAT ATG TCT CAA CCC GGC GGT CGG CCT AGC CTT GAC


CGC GCA CAT ACG TTT CCT ACG CCA CCT GCC AGT GCC TCG AGC GTT CCC AAC ACC CAG CCT CTG TCG ATC GAC ACG $\begin{array}{lllllllllllllllllllllllll}R & A & H & T & F & P & T & P & P & A & \text { S } & \text { A } & \text { S } & \text { S } & \text { V } & \text { P } & \text { N } & \text { T } & \text { Q } & \text { P } & \text { L } & \text { S } & \text { I } & \text { D } & \text { T }\end{array}$ 3075

AGT TTG AGT AAT GCA CGA TCA ATG CCC ACA ACC CCT GCT ACG ACG CCA CCT GGG AAC AAC CTG CAA GGC ATG CAG

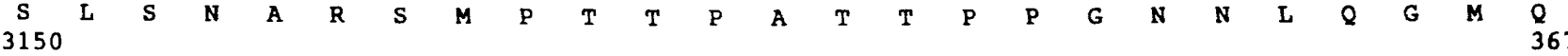
TCC TAC CAA CCC CAG TCC GGC TAC GAT TCG AAA CCA TAC TAC TCG GCC GCC CCG TCC ACG CAC CCC CAG TAC GCC $\begin{array}{lllllllllllllllllllllllll}S & Y & Q & P & Q & S & G & Y & D & S & K & P & Y & Y & S & A & A & P & S & T & B & P & Q & Y & A \\ 3225 & & & & & & & & & & & & \end{array}$ CCA CAA CAA CCA CTG CCC CAA CAG TCC ATG GCG CAG TAT GGC CAC TCT ATg CCA ACG AGC TCG TAT CGT GAC ATG $\begin{array}{lllllllllllllllllllllllll}\text { P } & Q & Q & \text { P } & \text { L } & \text { P } & Q & Q & \text { S } & \text { M } & \text { A } & Q & \text { Y } & \text { G } & \text { H } & \text { S } & \text { M } & \text { P } & \text { T } & \text { S } & \text { S } & \text { Y } & \text { R } & \text { D } & M\end{array}$ $3300 \quad 417$ GCG CCG CCC TCG TCG CAG CGT GGA TCT GTC ACC GAG ATC GAA TCT GAT GTC AAG ACG GAG CGC TAC GGC CAA GGC $\begin{array}{clllllllllllllllllllllllll}A & \text { P } & \text { P } & \text { S } & \text { S } & \text { Q } & \text { R } & \text { G } & \text { S } & \text { V } & \text { T } & \text { E } & \text { I } & \text { E } & \text { S } & \text { D } & \text { V } & \text { K } & \text { T } & \text { E } & R & Y & G & Q & G \\ 3375 & & & & & & & & & & & & & \end{array}$ ACC GTT GCA AAG ACC GAA CCA GAG CAA GAG CAG GAg TAT GCT CAG CCT GAC AGT GGA TAC AAC ACT GGT CGG GGC


TCG TAC TAC ACC ACC AAC CCC TCG GTC GGC GGT CTC GCC CAC GAC CAT TCC CAG CTC ACG CCA GAC ATG ACG GGA $\begin{array}{lllllllllllllllllllllllll}S & Y & Y & T & T & N & P & S & V & G & G & \text { L } & \text { A } & \text { H } & \text { D } & \text { H } & \text { S } & \text { Q } & \text { L } & \text { T } & \text { P } & \text { D } & \text { M } & \text { T } & G\end{array}$ 3525

TCT CCC CAG CAG AAT GGT TCT GGA CGC ATG ACC CCT CGC ACG AGT AAT ACT GCT CCT CAG TGG GCT CCG GGA TAC


ACC ACC CCT CCT CGC CCC GCC GCT GCC AGT AGT CTG TAC AAC ATT GTC AGT GAC ACG CGA GGA ACG TCA GGC GCG

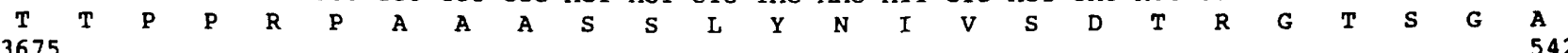
AAT GGA AGC ACC TCT GAC AaC TAT TCC GTC GCG TCT AaC TCT GGC TAC TCG ACt GGa ATG AaC GGC TCC ATG GGG

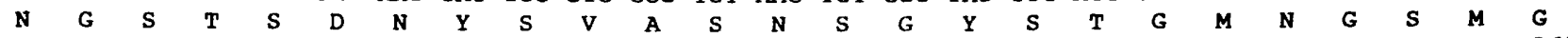
3750

TCC AAC AAG CGG ATG CGT GAT GAT GAT GAC GAC CGC ATT GTC CCA CCG GAC AGC CGT GGT GAA TTC GAT ACC AAG

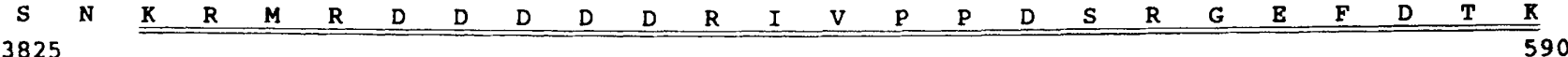
CGC CGG AAG ACC TTG ACA GAG ACC CCG GTT GGG GGT CCA GTA GGT GGT GTT CCT CTT GGG CTG CAG CAA TGA AGG $\begin{array}{lllllllllllllllllllllllll}R & R & K & T & L & T & E & T & P & V & G & G & P & V & G & G & V & P & L & G & I & Q & Q & \text { end }\end{array}$ 3900 CGG GTG GCA GTC TGA TAA GTGCTCGTCGTTAATTGCGAAAGAGCTCAATATCAACAAAGAAAAAAAAAGGTGTGGCGGGCAAGGAGCAAGCGGG end end

3993

GGTTGGTTGAGTTGGGCTACGGGTTGAGTATTTTCTCGGGGGTGCATTCTGGTTTTTCCTCTCTAATAGAACACGCTGGCATTGTTGAGCATCAGGCTTG 4093

ATGACTCGACTACAACGCTTACTCGCGCCGTATGGAAGTTAGACATGACTGGGACGCCTGGTCTTGGCATGGTTGAGGTTTATCATGGGATTCTGGCCAT 4193

AAAGTTGCGTGATGACTTGCAAAAAGGATGTGTATTCTGGGTCTGTTTCTTGTGCAGCGTTCTGAAGTCGCCTCTCCGCTTTTCGGCTGTCGCTAGACGC 4293

CTATGCTTGTTTGCGGCCGGCTTTATTATGACCATGATGAGACGAATTTCCTTCGAGCTATC TACATTGTTTGTCTTATagcttcttgtcgtattgtag 4393

atgcagtagctgctcaatctgattgcccaggttgcgagccetctagtgtttaaggatgcatgcataaagggcgggccgggaaggaacctccatcctagga 4493

gaatacggtaagcaactccgcaatctcagacc

Figure 2. Nucleotide sequence of the $s t u A$ gene. Numbers at left of each line indicate nucleotide positions; numbers at right indicate amino acid residues. Transcription initiation sites for $s t u A \alpha$ and $s t u A \beta$ are marked $>$ and *, respectively. Exon sequences of the $\beta$ transcript are uppercase letters and introns are lowercase. (Note that the first 100 nucleotides of the $\alpha$ transcript are also in lowercase letters, indicating that initiation is within the first intron of stuA $\beta$.) Mini-ORFs are underlined. Potential TATA and CAAT sequences are indicated by dots above sequences. A potential nuclear targeting sequence is double-underlined. The $3^{\prime}$ ends of both $\alpha$ and $\beta$ transcripts are identical and are indicated by \#. The GenBank accession number for this sequence is M83569. 
analysis with scanning densitometry of X-ray films from either Northern blot or primer extension experiments yielded similar results. The constitutively expressed $\arg B$ gene was used as an internal contol to standardize RNA sample loadings and for direct comparison of stuA signals between lanes (see Materials and methods).

\section{Spatially localized changes in StuA expression} are dependent on both induction and BrlA

Strain UI38.1 is a transformant that carries a single copy of the $\operatorname{stu} A(\mathrm{p} / \mathrm{l}):: \operatorname{lac} Z$ translational fusion gene integrated at the $\operatorname{trp} C$ locus on chromosome VIII. All genetic loci affecting conidiophore and conidia morphogenesis (including $\operatorname{stu} A$ ) in this strain are wild type. This strain expressed very low levels of StuA: $\beta$-Gal activity $(1-2$ units sp. act.) prior to developmental competence. /We use the abbreviations StuA: $\beta-G a l, A b a A: \beta-G a l$, and $\mathrm{BrlA}: \beta$-Gal to distinguish $\beta$-galactosidase expressed from the $\operatorname{stu} A(\mathrm{p} / \mathrm{l}):: 1 a c Z, a b a A(\mathrm{p} / 1):: 1 a c Z$, and $b r l A(\mathrm{p} / \mathrm{l}):: 1 a c Z$ reporter genes.) Expression increased $\sim 50$-fold (to 120 units sp. act.) in developmentally competent, but undifferentiated, vegetative hyphae (Fig. 4). StuA is required throughout conidiophore morphogenesis but not for vegetative growth. Therefore, it was possible that StuA: $\beta$ Gal expressed in uninduced mycelia was localized in specific cell types, such as foot cell initials or cleistoth- ecial initials. In situ localization indicated that this was not the case, the fusion protein being uniformly distributed throughout undifferentiated hyphae (data not shown).

We constructed two additional strains to confirm the temporal and spatial patterns of reporter gene expression observed for UI38.1. One strain, UI37.1, was a transformant in which the plasmid p2KLAC/TRP (Fig. 3B) had undergone homologous integration at the stuA locus on chromosome I. In this strain, the fusion gene has all chromosomal sequences normally found $5^{\prime}$ of the stu $A$ $\alpha / \beta$ start sites. The temporal and spatial pattern of $s t u A$ $\alpha / \beta$ RNAs, stuA(p/1)::lacZ RNAs, and StuA: $\beta$-Gal activity in UI37.1 was identical to UI38.1, indicating that the fusion gene construct had all sequences necessary for correct regulated expression (data not shown). A second strain, UI83, was constructed to determine whether UI38.1 possessed any secondary mutations that had resulted from either protoplast preparation or transformation and that might affect reporter gene expression. UI83 was a progeny of a genetic cross with UI38.1 as one of the parental strains. We observed that temporal and spatial expression of the reporter gene was identical to UI38.1 (data not shown).

The reporter gene was used to determine whether expression of the stuA gene might include post-transcriptional regulatory mechanisms, as suggested by the struc-

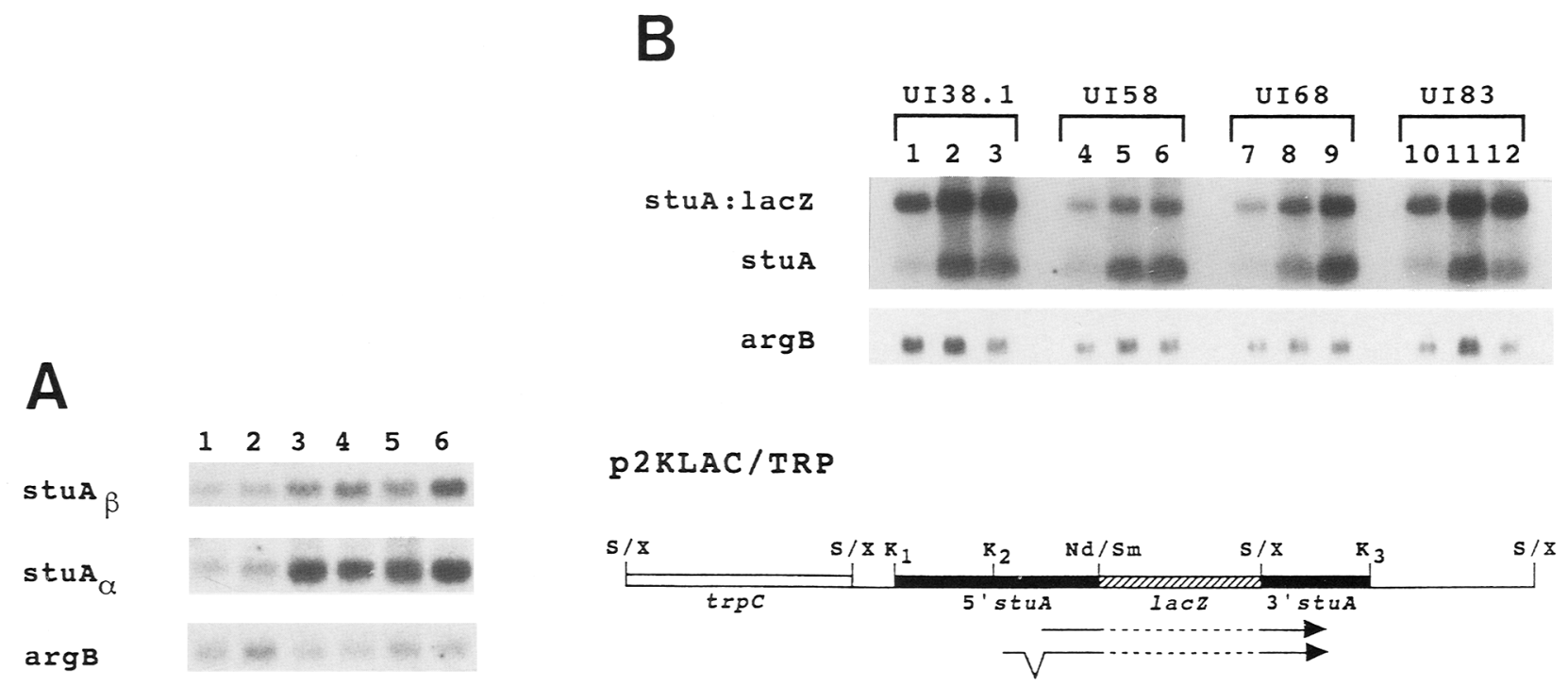

Figure 3. Expression of $s t u A \alpha$ and $s t u A \beta$ transcripts during induction of wild-type and brlA mutant strains. $(A)$ Northern blot of poly $\mid \mathrm{A})^{+}$RNAs isolated from the wild-type control strain FGSC 26. End-labeled oligonucleotide 395 was used for the $s t u A \beta$-specific probe; oligonucleotide 974 was used for the $s t u A \alpha$-specific probe. Northern blots were reprobed with a random-primed $a r g B$ probe for internal standardization of RNA samples. (Lane 1) Uninduced vegetative hyphae; (lanes 2-6) cultures isolated 2.5, 5, 7.5, 10, and 14 hr after induction. $(B)$ Northern blot of poly $(A)^{+}$RNAs isolated from either wild-type strains UI38.1 and UI83, the null brlAl mutant strain UI58, or the conditional brlA42 ${ }^{\text {ts }}$ mutant strain UI68. UI68 was grown at the nonpermissive temperature for these experiments. Blots were probed simultaneously with a random-primed $\arg B$-specific probe and the internal XbaI-XhoI stuA-specific probe. Duplicate samples were used for the in vitro assays of $\beta$-galactosidase activity shown in Fig. 4 . All strains possess the $s t u A(\mathrm{p} / 1):: l a c Z$ fusion gene integrated at the $\operatorname{trp} C$ locus. (stuA::lacZ) The fusion gene transcript. (Lanes 1,4,7,10) Uninduced hyphae; $($ lanes 2,5,8,11) 7.5-hr developmental cultures; (lanes 3,6,9,12) 14-hr developmental cultures. p2KLAC/TRP is the plasmid used for construction of UI38.1 (see Materials and methods). Thin lines are pBR329 sequences. (Kl-K3) The three KpnI sites shown in Fig. 1. (Sm) Smal; (S/X) SalI-Xhol fusion. 

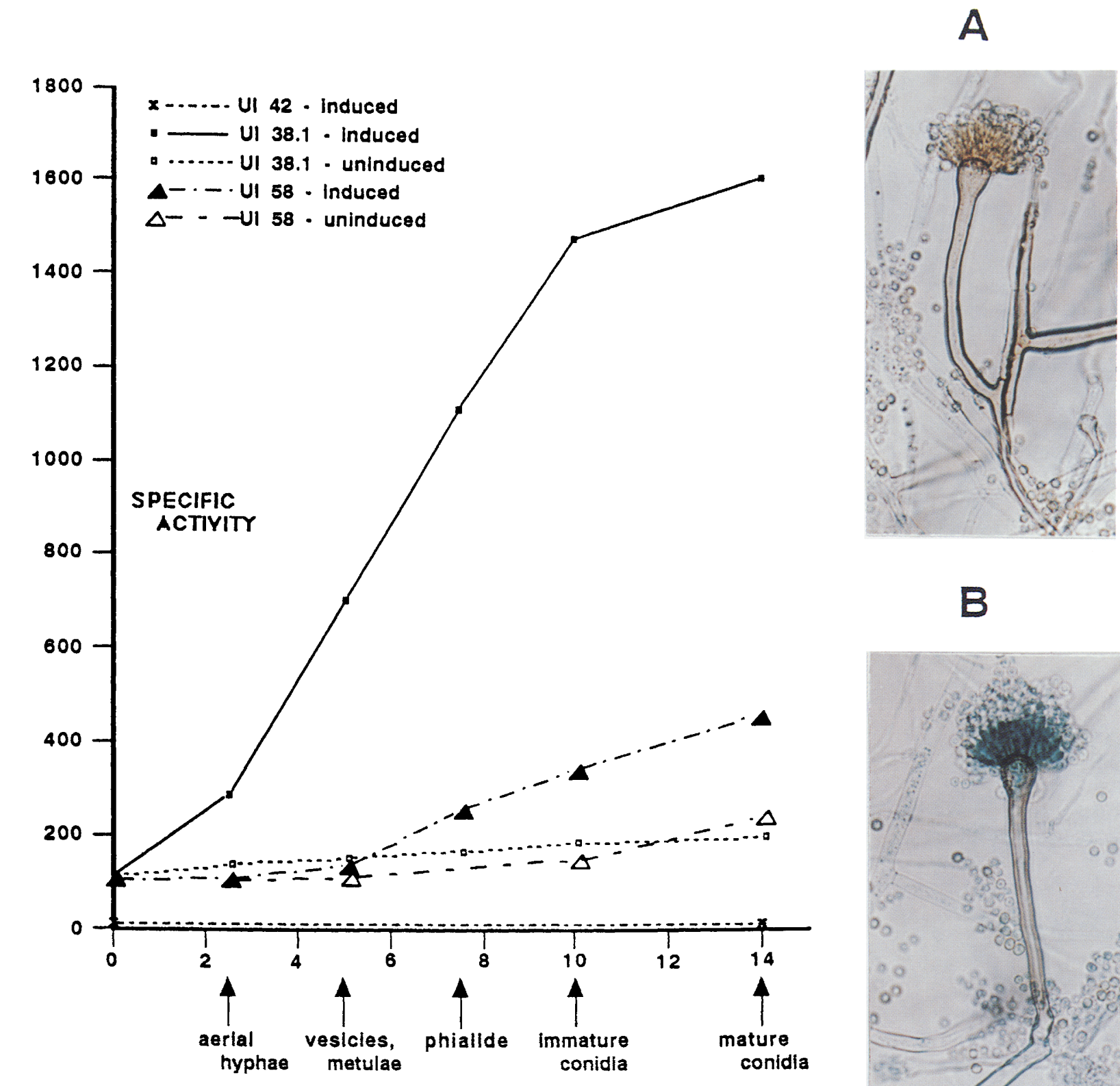

HRS. POSTINDUCTION

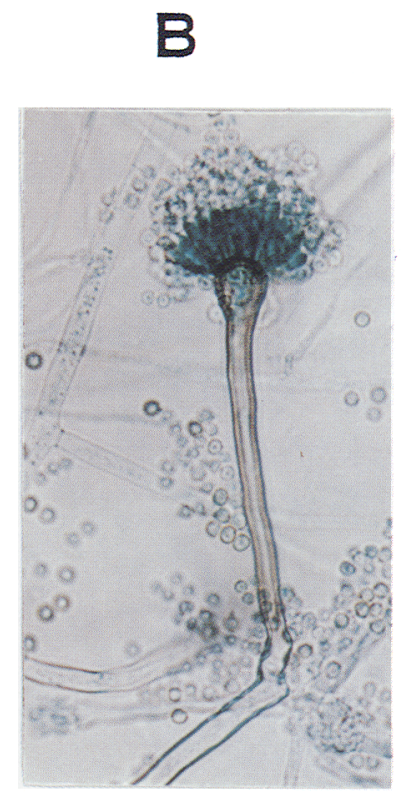

Figure 4. Temporal expression and spatial localization of the $s t u A(\mathrm{p} / 1):: 1 a c Z$ reporter gene in induced wild-type and $b r l A$ mutant strains. Cultures of indicated strains were isolated at various time intervals after induction and in vitro StuA: $\beta$-galactosidase specific activity determined in crude extracts. (Specific activity) Units of ONPG hydrolyzed/min per mg of total protein. Duplicate samples were used for the Northern blot analysis shown in Fig. 3B. Strains UI83 and UI68 (not shown) had temporal and spatial patterns of expression identical to UI38.1 and UI58, respectively. Morphological landmarks are indicated by arrows. Photomicrographs are conidiophores which have been stained with the chromogenic $\beta$-galactosidase substrate X-Gal. (A) Control strain UI42; (B) strain UI38.1.

ture of the mRNA leaders. Synchronously induced conidiation resulted in a 15 -fold increase in in vitro StuA: $\beta$-Gal activity during the $14 \mathrm{hr}$ required to complete the asexual cycle (Fig. 4). After an initial lag, the maximum increase in activity occurred during morphogenesis of the metulae and phialides. Vegetative hyphae maintained in an undifferentiated state for an additional
$14 \mathrm{hr}$ exhibited only a slight increase in StuA: $\beta$-Gal activity (Fig. 4), which was distributed uniformly throughout the mycelium (data not shown).

Two observations suggested that BrlA may enhance StuA expression. First, the temporal pattern of the induction-dependent increase in StuA: $\beta$-Gal expression was similar to that of BrlA expression (Boylan et al. 1987; 
Aguirre et al. 1990|. Second, in situ localization with the chromogenic substrate X-gal showed that these elevated levels of fusion protein were spatially restricted to the apex of the conidiophore vesicle, metulae, and phialides (Fig. 4). Only negligible amounts of StuA: $\beta$-Gal were detected in conidia. Therefore, except in immature conidia, the spatial localization of StuA: $\beta$-Gal overlapped that of BrlA: $\beta$-Gal (Aguirre et al. 1990). Strains UI58 and UI68 have the $\operatorname{stu} A(\mathrm{p} / 1):: 1 a c Z$ reporter gene and either the brlAl null allele or the brlA42 $2^{\text {ts }}$ allele, respectively. The loss of brlA function resulted in the failure of StuA: $\beta$ Gal expression to respond normally to inductive stimuli (Fig. 4). At 14 hr postinduction, expression of StuA: $\beta$-Gal in UI58 was only $25 \%$ that of UI38.1 (Fig. 4) and was uniformly distributed throughout the elongated aerial hyphae characteristic of bristle null mutants /data not shown). We did detect a fourfold increase in StuA: $\beta-G a l$ activity in induced UI58 cultures that was induction dependent and $b r l A$ independent. This increase, however, was delayed by $2.5-3 \mathrm{hr}$ (Fig. 4). Similar results were observed for UI68 induced under nonpermissive conditions.

The relative abundance of the fusion RNAs was significantly greater than the wild-type stuA RNAs in either UI38.1 or U183. This was particularly true for competent, undifferentiated hyphae (Fig. 3B). Whereas total wild-type stuA RNA increased about fivefold after induction, the change in fusion RNA was much smaller, about twofold. Furthermore, the presence of either brlAl or brlA $42^{\text {ts }}$ mutations resulted in a reduction in induced levels of fusion RNA in UI58 and UI68 but had only a slight, or no, effect on levels of wild-type stuA RNA (Fig. 3B|. The explanation for this observation is unknown but may result from differences in the stability of fusion and wild-type RNAs after induction. Ectopic expression of BrlA results in both activated transcription of conidiation-specific genes and transcriptional and post-transcriptional repression of metabolic genes (Adams et al. 1988; Adams and Timberlake 1990a). Therefore the stability of the stuA wild-type and fusion RNAs may be differentially affected when BrlA is expressed during normal conidiation.

\section{StuA is required for correct spatial expression of the abaA gene}

The $a b a A$ gene product is required for correct differentiation of the conidiogenic phialide and mature conidia (Clutterbuck 1969; Sewall et al. 1990). It has been suggested that the conidiophore morphology of stuA mutants is a function of incorrect temporal or spatial expression of phialide-specific genes such as $a b a A$. The result is a failure to differentiate metulae or phialides, and conidia are produced from buds on the conidiophore vesicle (Martinelli 1979; Miller et al. 1991). Strain UI49 was constructed to test this hypothesis. This strain possesses both an $a b a A(\mathrm{p} / 1):: 1 a c Z$ reporter gene integrated at the $\arg B$ locus on chromosome III and a stuAl null mutation.

The control strain TTA573 did not express AbaA: $\beta$ -
Gal activity in undifferentiated vegetative hyphae (Fig. 5; Adams and Timberlake 1990b). After induction, there was a slight increase in AbaA: $\beta$-Gal activity during elaboration of the aerial hyphae, conidiophore vesicles, and metulae. There was a dramatic increase in activity, however, which began at the onset of phialide differentiation ( $\sim 7.5 \mathrm{hr}$ postinduction) and continued during conidia formation (Fig. 5). AbaA: $\beta$-Gal was localized in metulae, phialides, and immature conidia and was absent from vegetative hyphae, foot cells, aerial hyphae, conidiophore vesicles, and mature conidia (Fig, 5A,B).

The temporal pattern of AbaA: $\beta$-Gal expression in strain UI49 was identical to that of TTA573 (Fig. 5). The level of expression was also very similar, being only slightly reduced in UI49. Therefore, the absence of StuA did not appear to have a major effect on the temporal expression of the reporter gene or, by inference, the resident $a b a A$ gene. However, there were significant alterations in the spatial localization of AbaA: $\beta$-Gal expression. No AbaA: $\beta$-Gal activity was detected in somatic hyphae of strains TTA573 or UI49 prior to induction. After induction, however, activity was detected throughout somatic hyphae, foot cells, aerial hyphae, and conidiophore vesicles of immature conidiophores of UI49 (Fig. 5D). AbaA: $\beta$-Gal expression was also observed throughout the fully differentiated conidiophores of UI49 (Fig. $5 E, F)$.

\section{Discussion}

StuA is required during two critical stages in the $A$. nidulans life cycle. Shortly after the establishment of developmental competence, asexual reproduction is initiated. StuA is required at this time for normal patterns of cell differentiation during conidiophore morphogenesis. Sexual reproduction begins as conidiation is completed (Champe et al. 1992). Meiosis and ascospore formation take place within specialized reproductive structures (cleistothecia) (Benjamin 1955). Sexual reproduction can take place in the absence of conidiation and does not require BrlA (Clutterbuck 1969; B. Miller, unpubl.). stuA mutants, however, are self-sterile and fail to form either cleistothecial primordia or associated nurse cells (Hulle cells) (Clutterbuck 1969; Miller et al. 1991). The complex structure and regulated expression of the $s t u A$ gene may reflect multiple roles during the life cycle. In this respect, stuA is similar to complex genes in higher eukaryotes that are required for morphogenesis /Gehring 1987; Biggin and Tjian 1989; Coen et al. 1990; Hayashi and Scott 1990; Schwarz-Sommer et al. 1990; Drews et al. 1991).

Precompetent hyphae of strain UI38.1 expressed low levels of $\beta$-galactosidase $(1-2$ units of $\beta-\mathrm{Gal} / \mathrm{min}$ per milligram of protein), whereas activity was $\sim 50$-fold higher in competent, uninduced hyphae. Therefore, during this stage of development, the level of StuA: $\beta-$ Gal activity closely paralleled changes in the relative abundance of stuA $\alpha / \beta$ RNAs. Two lines of evidence indicate that a component of stuA expression includes induction-dependent, post-transcriptional regulation. Between 2.5 




Figure 5. Temporal expression and spatial localization of the $a b a A \mid \mathrm{p} / \mathrm{l}): 1 a c Z$ reporter gene in induced wild-type and stuA mutant strains. Induced cultures were isolated at the same time intervals as in Fig. 4, and the specific activity of AbaA: $\beta$-galactosidase was determined. (Specific activity) Units of ONPG hydrolyzed/min per $\mathrm{mg}$ of protein. Photomicrographs were stained with X-Gal to determine the in situ localization of the fusion protein. (A) A young conidiophore of wild-type strain TTA573 that is beginning to form the terminal vesicle; $(B)$ a mature TTA573 conidiophore; $(C)$ control strain GO256 containing no fusion gene; $(D)$ young conidiophore of UI49 at same stage as in $A ;(E, F)$ mature UI49 conidiophores.

and $7.5 \mathrm{hr}$ postinduction, StuA: $\beta$-Gal specific activity in UI38.1 (or UI83) increased at a linear rate that was $\sim 30$ times that observed for cultures maintained vegetatively. One would predict a similar increase in total stuA $(\alpha+\beta)$ RNA if the translational initiation rate remained constant during conidiation and the change in $\beta$-Gal activity was directly related to changes in RNA abundance. Semiquantitation by scanning densitometry indicated 
that total stuA RNA abundance increased approximately three- to fourfold and total stuA:lacZ RNA increased about twofold during this time. We do not know whether these changes are the result of increased transcription or altered RNA stability. Although enhanced cell-specific expression of StuA: $\beta$-Gal may be partially explained by these small changes in RNA abundance, there was not a close correlation between stuA:IacZ RNA abundance and $\beta$-Gal specific activity.

Both stuA RNAs possess long 5' leaders with multiple mini-ORFs. These structural elements have been shown to be important for the post-transcriptional regulation of mRNAs from yeast (Hinnebusch 1984; Thireos et al. 1984; Mueller and Hinnebusch 1986; Werner et al. 1987; Tzamarias et al. 1989) and vertebrates (Kozak 1984, 1987; Garrett et al. 1989; Arrick et al. 1991). Translation of the stuA $\alpha$-specific mORF 1 would yield a $2.8-\mathrm{kD}$ peptide (LP1). We have found that translational fusion of the lacZ gene to the end of mORF 1 results in expression of an LP1: $\beta$-Gal fusion protein. The integrity of mORF 1 is required for the induction-dependent increase in StuA: $\beta$ Gal activity (J. Wu and B. Miller, in prep.). Therefore, translation of mORF 1 appears to have a regulatory function and suggests that the $\alpha$ and $\beta$ transcripts may have different translational efficiencies. Functional analysis of $5^{\prime}$ RNA leader sequences will clarify the contribution of post-transcriptional regulatory mechanisms to stuA expression.

Although clear epistatic relationships exist among members of either the BRISTLE or STUNTED group of genes, double mutant strains carrying a defective allele in both groups have complex morphologies with intermediate characteristics. Conidiophore morphology is also dependent on the specific alleles used (Martinelli 1979). Martinelli interpreted these results as evidence for complex interactions and possible overlap in functions between the two groups of genes.

BrlA is required for the transition from a vegetative growth pattern of apical extension to a budding pattern of growth and to direct conidia differentiation (Clutterbuck 1969; Boylan et al. 1987; Adams et al. 1988). We have found that BrlA is also required for the inductiondependent, spatially localized increase in StuA: $\beta$-Gal expression. There was a $75 \%$ reduction in StuA: $\beta-\mathrm{Gal}$ activity in the $\operatorname{brl} A 1$ and $\operatorname{brl} A 42^{\text {ts }}$ mutant strains. The fourfold increase in activity that did occur in UI58 or UI68 was delayed $2.5-3 \mathrm{hr}$ relative to the wild-type strain UI38.1. Our interpretation of the exact quantitative effect of brlA mutations is confounded by apparent differences in the stability of stuA and stuA:lacZ RNAs after induction. A comparison of temporal changes in the fusion RNA and StuA: $\beta$-Gal activity, however, reinforces earlier observations that there is not a strict correlation between RNA abundance and activity. BrlA probably does not have a direct effect on StuA expressicn. Ectopic expression of brlA results in the inhibition of vegetative growth, the transcriptional activation of a large number of conidiation-specific genes, and the repression of certain catabolic genes at both the transcriptional and post-transcriptional level (Adams et al. 1988;
Adams and Timberlake 1990a). Our results suggest that BrlA-induced events also result in the selective activation of important developmental genes, such as $\operatorname{stu} A$, at the post-transcriptional level.

Martinelli (1979) has suggested that the stunted phenotype could result from incorrect temporal or spatial expression of genes coding for phialide-specific functions. We considered the $a b a A$ gene to be a likely candidate for such aberrant expression because of its central role in phialide differentiation. Furthermore, functional analysis of $a b a A$ cis-acting regulatory sequences has revealed complex features that include elements required for spatial restriction of $a b a A$ expression to metulae, phialide, and immature conidia (Adams and Timberlake 1990b). stuA null mutations do not appear to have a significant temporal or quantitative effect on the expression of the $a b a A(\mathrm{p} / 1):: l a c Z$ reporter gene. Loss of StuA function, however, results in the uniform distribution of AbaA: $\beta$-Gal throughout the reduced conidiophore, including foot cells, aerial hyphae, and conidia. Our results suggest that StuA is required to establish a spatial, cellspecific gradient of $a b a A$ expression during conidiation. The precise molecular mechanisms involved are unknown; however, the effect may be indirect. BrlA is necessary and sufficient to activate $a b a A$ expression. It has been shown recently that StuA is also required for correct spatial, but not temporal, expression of brlA (J. Aguirre and W.E. Timberlake, pers. comm.). Therefore, in a stu $A$ null mutant, brlA expression is still activated in response to unknown induction signals, but the spatial gradient is not established. This, in turn, could result in incorrect spatial expression of $a b a A$ and aberrant morphogenesis. The highly simplified conidiophores of a stuA null mutant mimic the conidia-bearing structures formed during ectopic overexpression of BrlA (Adams et al. 1988; Mirabito et al. 1989).

The temporal and spatial patterns of StuA and BrlA expression are similar during morphogenesis. Therefore, it is unlikely that StuA is acting directly to repress brlA expression. Although various interpretations are possible, the simplest model would involve repression of brlA by a currently uncharacterized repressor, X. StuA would, in turn, repress $\mathrm{X}$ expression or function. Thus, an increasing gradient in StuA expression would be able to establish a spatial gradient in BrlA expression. Maintenance of this gradient could be self-regulating by means of the positive effect of $\mathrm{BrlA}$ (either direct or indirect) on StuA expression. Alternatively, StuA may be necessary for the expression of a factor that blocks the function of repressor $\mathrm{X}$. Indirect evidence for the role of StuA in transcriptional activation comes from observations that certain classes of RNAs expressed in induced cultures of wild-type strains are not expressed in stuA1 mutant strains (Zimmermann 1986; K. Miller and B. Miller, unpubl.). The function of StuA in somatic hyphae is unknown but may be related to its role in the sexual reproductive cycle.

Conidiation in $A$. nidulans has been shown to require transcriptional activation of a complex regulatory hierarchy that is initiated by BrlA and that includes at least 
two feedback regulatory loops (Adams et al. 1988; Mirabito et al. 1989). Our results show that both transcriptional and post-transcriptional regulatory mechanisms play important roles during conidiophore morphogenesis. We have also shown that normal patterns of cell differentiation in $A$. nidulans do not result from a simple linear progression of gene activation but require spatial modulation of the BrlA-activated pathway by functions of StuA. The four genes $(a b a A, b r l A, \operatorname{med} A$, and $s t u A)$ that are critical to morphogenesis have been isolated and can now be subjected to detailed molecular genetic analysis to test regulatory models. Reproductive competence in A. nidulans is not well understood (Miller 1990; Timberlake 1990). Therefore, an analysis of cis-acting elements and trans-acting factors required for competencedependent stuA transcription should provide important insights into the molecular genetic basis for this critical stage of the $A$. nidulans life cycle.

\section{Materials and methods \\ Culture, developmental induction, and genetic manipulation of A. nidulans}

Procedures for the preparation of supplemented minimal media and for the culture of $A$. nidulans were performed as described by Kafer (1977) and Pontecorvo et al. (1953). Standard genetic manipulations used in this study followed methods described by Clutterbuck (1974) and Pontecorvo et al. (1953). Strains AJC7.1 and GO256 were obtained from A.J. Clutterbuck (University of Glasgow, Scotland). Strain TTA573 was received from T.H. Adams (Texas A\&M University, College Station, TX). Strains designated FGSC are available from the Fungal Genetics Stock Center (University of Kansas Medical Center, Kansas City). Strains designated UI were constructed at the University of Idaho (Table 1).

Silanized flasks containing liquid YG-MTV media were inoculated with $5 \times 10^{6}$ conidia per milliliter. Shake cultures were grown for $17 \mathrm{hr}$ at $37^{\circ} \mathrm{C}$. Mycelia acquired developmental competence after $13 \mathrm{hr}$ but remained in a vegetative state (Miller et al. 1991). Synchronous conidiation can be induced by exposing undifferentiated hyphae to an air interface. Hyphae were collected onto nylon mesh and placed onto solid agar media. Foot cell initials cannot be detected microscopically but are believed to be formed shortly after induction. Aerial hyphae were observed after $2.5 \mathrm{hr}$, vesicle and metulae initials after $5 \mathrm{hr}$, metulae and phialides after $7.5 \mathrm{hr}$, immature conidia after $10 \mathrm{hr}$, and mature pigmented conidia after 12-14 hr. Samples were collected at desired time intervals and frozen quickly in liquid $\mathrm{N}_{2}$.

\section{Construction of A. nidulans strains}

KpnI linkers were added to the PvuII site of the Escherichia coli plasmid pBR329. The two KpnI fragments encompassing the stuA gene (Fig. 1) were cloned into this vector. The resulting plasmid, pK6.8, was linearized with NdeI and blunt ends were generated with mung bean nuclease, restricted with $X$ hoI, and ligated to a gel-purified SmaI-Sall fragment containing the $E$. coli lacZ gene from pMC1871 (Casadaban et al. 1983). In this construct, $22 \mathrm{KLAC}, l a c Z$ is fused in-frame to codon 22 of the stuA ORF. Expression of $\beta$-galactosidase is therefore under the control of all of the upstream cis-acting DNA elements necessary for correct stuA $\alpha$ and stuA $\beta$ expression. This includes any post-transcriptonal regulatory mechanisms that involve elements of the $5^{\prime} \alpha$ and $\beta$ leaders. Two fusion RNAs, stuA $\alpha: l a c Z$ and $\operatorname{stu} A \beta: \operatorname{lac} Z$, are expressed from this fusion gene. p2KLAC was linearized by Sall partial digestion and ligated to the gelpurified $4.2-\mathrm{kb} X$ hol fragment containing the $A$. nidulans trpC gene. Plasmid p2KLAC/TRP (Fig. 3B) was used to transform $A$. nidulans strain FGSC237 to tryptophan prototrophy. Methods for DNA-mediated transformation of $A$. nidulans protoplasts were those of Yelton et al. (1984) and Miller et al. (1985). Miniprep DNA was isolated from transformants and Southern blot analysis was used to screen for single-copy integration events at the trpC locus (Miller et al. 1985, 1987). Transformant UI38.1 was selected for further studies. Strains UI58, UI68, and UI83 were obtained as progeny from a sexual cross between UI38.1 and AJC7.1, UI29, and TTA292, respectively. Strain UI49 was

Table 1. A. nidulans strains used in this study

\begin{tabular}{|c|c|c|}
\hline Strain & Genotype & Source \\
\hline FGSC 26 & biAl & Fungal Genetics Stock Center \\
\hline FGSC 237 & pabaA1, yA2; trpC801 & Fungal Genetics Stock Center \\
\hline AIC 7.1 & biA $1 ;$ brlal & Clutterbuck |1969| \\
\hline GO 256 & stuAl, biAl & Clutterbuck (1969) \\
\hline TTA 292 & biA $1 ;$ methG1; alcA $(\mathrm{p}):: b r L A\left(\arg B^{+} / \arg B:: C A T\right)$ & Adams et al. (1988) \\
\hline TTA 573 & biAl; meth $G 2 ; a b a A(\mathrm{p} / 1):: \operatorname{IacZ}\left(\arg B^{+} / \arg B: \mathrm{CAT}\right)$ & Adams and Timberlake (1990b) \\
\hline UI 8 & stuAl, biA1; trpC 801 & this study \\
\hline UI 29 & biAl; brlA42ts $\operatorname{trp} C 801$ & this study \\
\hline UI 37.1 & $\operatorname{paba} A 1$, yA2, stuA $(\mathrm{p} / 1):: \operatorname{lac} Z\left(\operatorname{trp} C^{+} / \operatorname{stu} A^{+}\right)$ & this study \\
\hline UI 38.1 & pabaA1, yA2, stuA $\{\mathrm{p} / 1\}:: 1 a c Z\left\{\operatorname{trp} C^{+} / \operatorname{trp} C 801\right)$ & this study \\
\hline UI 42 & pabaA1, yA2 & \\
\hline UI 49 & stuA1, biA1; methG $2 ; a b a A(\mathrm{p} / 1): \operatorname{lacZ}\left(\arg B^{+} / \arg B:: \mathrm{CAT}\right)$ & this study \\
\hline UI 58 & pabaA $1 ;$ brlA $1, \operatorname{stuA}(\mathrm{p} / 1):: \operatorname{lac} Z\left\{\operatorname{trp} C^{+} / \operatorname{trp} C 801\right)$ & this study \\
\hline UI 68 & pabaA $;$ brlA42 ${ }^{\mathrm{ts}} ;$ stuA $(\mathrm{p} / 1):: \operatorname{lacZ}\left(\operatorname{trp} C^{+} / \operatorname{trp} C 801\right)$ & this study \\
\hline UI 83 & biAl; $\operatorname{stu} A(\mathrm{p} / 1):: \operatorname{lacZ}\left(\operatorname{trp} C^{+} / \operatorname{trp} C 801\right)$ & this study \\
\hline
\end{tabular}

Abbreviations: $(a r g)$ arginine; $(b i)$ biotin; (meth) methionine; $(p a b a)$ p-aminobenzoic acid; $($ trp $)$ tryptophan; $(a b a A)$ abacus; $(b r l A)$ bristle; (stuA) stunted; $(y A)$ yellow conidia; (lacZ) E. coli $\beta$-galactosidase. All strains are veA l: velvet morphology. (p/l) A translational fusion that places $\beta$-galactosidase expression under the control of potential cis-regulatory elements present in the promoter and the 5 ' RNA leader of the heterologous gene. $\left(\operatorname{trp} C^{+} / \operatorname{trpC801)}\right.$ The $\operatorname{trp} C^{+}$transforming plasmid integrated by homology at the $\operatorname{trp} C$ locus. 
the result of a cross between TTA573 and U18. During construction of these strains, ascospore progeny were replica plated onto solid agar media in glass petri dishes. After 2 days of growth at $37^{\circ} \mathrm{C}$, the cultures were treated with chloroform vapors and the presence of the $\operatorname{stuA}(\mathrm{p} / \mathrm{l}):: 1 a c Z$ fusion gene was detected by in situ staining as described below.

In vitro assay and in situ localization of $\beta$-galactosidase activity

Specific activity of $\beta$-galactosidase in $A$. nidulans crude cell extracts was determined by use of the ONPG assay described by Miller (1972), as modified by Hamer and Timberlake (1987). Cultures were grown for in situ detection of fusion gene expression by point-inoculating conidia onto thin layers of minimal media contained in sterile chamber culture slides (Nunc, Inc., Naperville, IL). Cultures were allowed to grow for 2-3 days at $37^{\circ} \mathrm{C}$. The chambers were then inverted over chloroform-soaked filter paper for 10-15 min to permeabilize the conidiating cultures. Chloroform vapors were allowed to dissipate. The chambers were flooded with buffered X-gal and incubated at $37^{\circ} \mathrm{C}$ for 30-60 min to allow color development (Adams and Timberlake 1990b; Aguirre et al. 1990). The chambers were drained, and bright-field photomicrographs were taken with a Zeiss Axioplan.

$S 1$ nuclease protection, primer extension, and isolation of PCR-generated CDNA clones of stuA $\alpha$ and stuA $\beta$

The following synthetic oligonucleotides were used for S1 nuclease protection, primer extension, or RNA sequencing experiments: oligo 395, 5'-GTCTGTCTGAGACGGATGTAGCTGCAAGGC-3'; oligo 974， 5'-GAGTTGGGAGGTCATTAGTCGTAGCGGGCA-3'; oligo 1139, 5' ${ }^{\prime}$-CCGACTTGGACAGACAGAGAAGCAGACGGC-3'; oligo 1460, 5'-CACGGAGAAGCTTCG-3'; oligo 1699, 5' -GACAACAGAGGTCGCTCCGCGGCGTGGTGA-3'; oligo 2000, 5'-TTCATGCTGGCCATC-3'; oligo 2480, 5' -GACACCCTTGGCTTC-3'; oligo 2640, 5'-TTTCGGACCTTTTCACTCTTGAGGATACCG-3'; oligo 2855, 5'-GTCATGTTCCTCTGATTCTGGTTCGCCGGG-3'.

The sequences represent the template strand, and the number designates the position of the $5^{\prime}$ nucleotide on the sequence in Figure 2.

Previously, we have described the $\mathrm{S} 1$ nuclease mapping of the stuA gene (Miller et al. 1991). In this study we have located intron-exon junctions precisely by using the method of Burke (1984) to position 3 ' intron junctions and then using synthetic oligonucleotides to directly sequence the $s t u A$ mRNA in this region (Geleibter et al. 1986). We confirmed the structure of the nontranslated leader sequences common to both stuA $\alpha$ and $\operatorname{stu} A \beta$ by sequencing the RNA with oligonucleotides 1139 , 1460,1699 , and 2000 . RNA sequencing with oligonucleotide 1139 yielded an ambiguous nucleotide ladder once the se-


scriptional start sites were determined by comparing $\mathrm{S} 1 \mathrm{nu}$ clease-protected fragments derived from Burke probes made with oligonucleotide 1139 , and primer extension products were generated with oligonucleotides 395,974 , and 1139 . In all cases, transcriptional start sites for RNAs isolated from either undifferentiated hyphae or developmental cultures were the same.

The structural difference in the leaders of the $s t u A \alpha$ and stuA $\beta$ RNAs was confirmed by isolation of cDNAs corresponding to these sequences. Poly $(A)^{+}$RNA was isolated from vegetative hyphae or 14 -hr induced cultures. In separate reactions, cDNAs were first synthesized with oligonucleotide 1139 and subjected to polymerase chain reaction (PCR) amplification with oligonucleotide 1139 and a primer specific for either stuA $\alpha$ or stuAß: (stuA $\alpha$-specific) PCR 897, 5'-AGGGATCCGTCGCTCATCCTTTTTCGTC- ${ }^{\prime}$; (stuA $\beta$-specific) PCR 401, 5'-AGGGATCCACGCAGAGCACGACACGTGC- ${ }^{\prime}$.

These sequences represent the RNA-like strand, and the number designates the position of the $5^{\prime}$ nucleotide in the sequence of Figure 2A. The PCR-amplified products were cloned into Bluescript phagemid vectors.

Northern blot analysis, nucleic acid sequencing, and protein sequence analysis

Total and poly $(A)^{+}$RNA was isolated from A. nidulans as described previously (Timberlake 1980; Miller et al. 1987). Methods used for Northern blot analysis were the same as those of Miller et al. (1991). In these studies, end-labeled oligonucleotides 974 and 395 were used for the stuA $\alpha$-specific and stuA $\beta$ specific probes, respectively. Replicate blots were probed with both an $\arg B$-specific probe and either oligonucleotide 974 or 395. For total stu $A(\alpha+\beta)$ RNA determination, blots were probed simultaneously with the $\arg B$-specific probe and the internal $X b a \mathrm{I}-X h o \mathrm{I} s t u A$ fragment is shown in Figure 1. After determining that signal response was linear, different film exposure times were used to avoid film saturation and to maintain linearity in response. The intensity of bands was quantitated by using a Zeineh soft laser scanning densitometer. Peak areas for $s t u A \alpha$ and $s t u A \beta$ from different developmental time points were standardized with the constitutively expressed argB RNA as an internal control. This allowed direct comparison from sample to sample and corrected for any sample loading variation.

To sequence the $s t u A$ gene, overlapping restriction fragments were subcloned into Bluescript $\mathrm{KS}\{+/-$ | phagemids (Stratagene Cloning Systems, La Jolla, CA). Nested deletions were generated by ExolII resection (Henikoff 1984). Single-stranded templates were sequenced with Sequenase (U.S. Biochemical Corp., Cleveland, OH). The PC GENE software package (IntelliGenetics, Mountain View, CA) was used for nucleotide and protein sequence analyses. Secondary structure predictions for the StuA protein were determined by use of the method of Garnier et al. (1978) and the Gascuel and Golmard Basic Statistical Method (Gascuel and Golmard 1988). Data base searches with either the nucleotide or amino acid sequences were provided by services offered through the Washington State University Visualization, Analysis and Design in the Molecular Sciences (VADMS) Laboratory (Pullman, WA).

\section{Acknowledgments}

We thank Drs. Jesus Aguirre and William E. Timberlake for sharing information prior to publication and Drs. Thomas $\mathrm{H}$. Adams, Nancy A. Federspiel, Scott A. Minnich, and David J. Oliver for many useful discussions and critical review of the manuscript. We also thank Dr. Susan Johns and Steve Thompson at the Washington State University VADMS Laboratory for their assistance in data base searches. This work was supported by National Science Foundation grant DCB 8819219 to B.L.M.

The publication costs of this article were defrayed in part by payment of page charges. This article must therefore be hereby marked "advertisement" in accordance with 18 USC section 1734 solely to indicate this fact.

\section{References}

Adams, T.H. and W.E. Timberlake. 1990a. Developmental re- 
pression of growth and gene expression in Aspergillus. Proc. Natl. Acad. Sci. 87: 5405-5409.

1990b. Upstream elements repress premature expression of an Aspergillus developmental regulatory gene. Mol. Cell Biol. 10: 4912-4919.

Adams, T.H., M.T. Boylan, W.E. Timberlake. 1988. brlA is necessary and sufficient to direct conidiophore development in Aspergillus nidulans. Cell 54: 353-362.

Aguirre, J., T.H. Adams, and W.E. Timberlake. 1990. Spatial control of developmental regulatory genes in Aspergillus nidulans. Exp. Mycol. 14: 290-293.

Arrick, B.A., A.L. Lee, R.L. Grendell, and R. Derynck. 1991. Inhibition of translation of transforming growth factor- $\beta 3$ mRNA by its $5^{\prime}$ untranslated region. Mol. Cell. Biol. 11: 4306-4313.

Axelrod, D.E., M. Gealt, and M. Pastushok. 1973. Gene control of developmental competence in Aspergillus nidulans. Dev. Biol. 34: 9-15.

Benjamin, C.R. 1955. Ascocarps of Aspergillus and Penicillium. Mycologia 47: 669-687.

Biggin, M.D. and R. Tjian. 1989. Transcriptional factors and the control of Drosophila development. Trends Genet. 5: 377383.

Boylan, M.T., P.M. Mirabito, C.E. Willet, C.R. Zimmermann, and W.E. Timberlake. 1987. Isolation and physical characterization of three essential conidiation genes from Aspergillus nidulans. Mol. Cell. Biol. 7: 3113-3118.

Burke, J.F. 1984. High sensitivity S1 mapping with singlestranded ${ }^{32}$ P]DNA probes synthesized from bacteriophage M13mp templates. Gene 30: 63-68.

Butnick, N.Z., L.N. Yager, T.E. Hermann, M.B. Kurtz, and S.P. Champe. 1984. Mutants of Aspergillus nidulans blocked at the early stage of sporulation secrete an unusual metabolite. I. Bacteriol. 160: 533-540.

Casadaban, M.J., A. Martinez-Arias, S.K. Shapira, and J. Chou. 1983. $\beta$-Galactosidase gene fusions for analyzing gene expression in Escherichia coli and yeast. Methods Enzymol. 100: 291-308.

Champe, S.P., M.B. Kurtz, L.M. Yager, N.J. Butnick, D.E. Axelrod. 1981. Spore formation in Aspergillus nidulans: Competence and other developmental processes. In The fungal spore: Morphogenic controls (ed. G. Turian and H.R. Hohl), pp. 255-276. Academic Press, New York.

Champe, S.P., D.L. Nagle, and L.N. Yager. 1992. Sexual sporulation in Aspergillus nidulans. In Genetics and physiology of Aspergillus (ed. S. Martinelli and J.R. Kinghorn). Chapman \& Hall, London, England. (In press.)

Clutterbuck, A.J. 1969. A mutational analysis of conidial development in Aspergillus nidulans. Genetics 63: 317-327.

- 1974. Aspergillus nidulans. In Handbook of genetics (ed. R.C. King), vol. 1, pp. 447-510. Plenum Press, New York.

- 1977. The genetics of conidiation in Aspergillus nidulans. In Genetics and physiology of Aspergillus (ed. J.E. Smith and J.A. Pateman|, pp. 305-317. Academic Press, London, England.

Coen, E.S., J.M. Romero, S. Doyle, R. Elliott, G. Murphy, and R. Carpenter. 1990. floricaula: A homeotic gene required for flower development in Antirrhinum majus. Cell 63: 13111322.

Drews, G.N., J.L. Bowman, and E.M. Meyerowitz. 1991. Negative regulation of the Arabidopsis homeotic gene $A G A$. MOUS by the APETALA2 product. Cell 65: 991-1002.

Garnier, J., D.J. Osguthorpe, and B. Robson. 1978. Analysis of the accuracy and implications of simple methods for predicting the secondary structure of globular proteins. I. Mol. Biol. 120: $97-120$.
Garrett, J.E., J.E. Collard, and J.O. Douglass. 1989. Translational control of germ cell-expressed mRNA imposed by alternative splicing: Opioid peptide gene expression in rat testis. Mol. Cell. Biol. 9: 4381-4389.

Gascuel, O. and J.L. Golmard. 1988. A simple method for predicting the secondary structure of globular proteins: Implications and accuracy. Comput. Appl. Biosci. 4: 357-365.

Gehring, W.J. 1987. Homeo boxes in the study of development. Science 236: 1245-1252.

Geleibter, J., R.A. Zeff, R.W. Melvoid, and S.G. Matheson. 1986. Mitotic recombination in germ cells generated two major histocompatibility complex mutant genes shown to be identical by RNA sequence analysis: $\mathrm{K}^{\mathrm{bm} 9}$ and $\mathrm{K}^{\mathrm{bm} 6}$. Proc. Natl. Acad. Sci. 83: 3371-3375.

Hamer, J.E. and W.E. Timberlake. 1987. Functional organization of the Aspergillus nidulans trpC promoter. Mol. Cell. Biol. 7: 2352-2359.

Hayashi, S. and M.P. Scott. 1990. What determines the specificity of action of Drosophila homeodomain proteins? Cell 63: $883-894$.

Henikoff, S. 1984. Unidirectional digestion with ExoIII creates targeted breakpoints for DNA sequencing. Gene 28: 351359.

Hinnebusch, A.G. 1984. Evidence for translational regulation of the activator of general amino acid control in yeast. Proc. Natl. Acad. Sci. 81: 6442-6446.

Kafer, E. 1977. Meiotic and mitotic recombination in Aspergillus and its chromosomal aberrations. Adv. Genet. 19: 33131

Kozak, M. 1984. Selection of initiation sites by eucaryotic ribosomes: Effect of inserting AUG triplets upstream from the coding sequence for preproinsulin. Nucleic Acids Res. 12: 3873-3893.

- 1987. An analysis of $5^{\prime}$ coding sequences from 699 vertebrate messenger RNAs. Nucleic Acids Res. 15: 8125-8148.

Marshall, M.A. and W.E. Timberlake. 1991. Aspergillus nidulans wet $A$ activates spore-specific gene expression. Mol Cell. Biol. 11: 55-62.

Martinelli, S.D. 1979. Phenotypes of double conidiation mutants of Aspergillus nidulans. Gen. Microbiol. 114: 277-287.

Martinelli, S.D. and A.J. Clutterbuck. 1971. A quantitative survey of conidiation mutants in Aspergillus nidulans. I. Gen. Microbiol. 69: 261-268.

Miller, B.L. 1990. The developmental genetics of asexual reproduction in Aspergillus nidulans. Sem. Dev. Biol. 1: 207-219.

Miller, B.L., K.Y. Miller, and W.E. Timberlake. 1985. Direct and indirect gene replacements in Aspergillus nidulans. Mol. Cell. Biol. 5: 1714-1721.

Miller, B.L., K.Y. Miller, K.A. Roberti, and W.E. Timberlake. 1987. Position-dependent and -independent mechanisms regulate cell-specific expression of the SpoC1 gene cluster of Aspergillus nidulans. Mol. Cell. Biol. 7: 427-434.

Miller, J.H. 1972. Experiments in molecular genetics. Cold Spring Harbor Laboratory, Cold Spring Harbor, New York.

Miller, K.Y., T.M. Toennis, T.H. Adams, and B.L. Miller. 1991. Isolation and transcriptional characterization of a morphological modifier: The Aspergillus nidulans Stunted (stuA) gene. Mol. \& Gen. Genet. 227: 285-292.

Mims, C.W., E.A. Richardson, and W.E. Timberlake. 1988. Ultrastructural analysis of conidiophore development in the fungus Aspergillus nidulans using freeze-substitution. Protoplasma 144: 132-141.

Mirabito, P.M., T.H. Adams, and W.E. Timberlake. 1989. Interactions of three sequentially expressed genes control temporal and spatial specificity in Aspergillus development. Cell 57: 859-868. 
Mitchell, P.J. and R. Tjian. 1989. Transcriptional regulation in mammalian cells by sequence-specific DNA binding proteins. Science 245: 371-378.

Mueller, P.P. and A.G. Hinnebusch. 1986. Multiple upstream AUG codons mediate translational control of GCN4. Cell 45: 201-207.

Pastushok, M. and D.E. Axelrod. 1976. Effect of glucose, ammonium and media maintenance on the time of conidiophore induction by surface colonies of Aspergillus nidulans. I. Gen. Microbiol. 94: 221-224.

Pontecorvo, G., J.A. Roper, L.M. Hemmons, K.D. MacDonald, and A.W.J. Bufton. 1953. The genetics of Aspergillus nidulans. Adv. Genet. 5: 141-238.

Robbins, J., S.M. Dilworth, R.A. Laskey, and C. Dingwall. 1991. Two interdependent basic domains in Nucleoplasmin nuclear targeting sequence: Identification of a class of bipartite nuclear targeting sequence. Cell 64: 615-623.

Schwarz-Sommer, Z., P. Huijser, W. Nacken, H. Saedler, and H. Sommer. 1990. Genetic control of flower development by homeotic genes in Antirrhinum majus. Science 250: 931936.

Sewall, T.C., C.W. Mims, and W.E. Timberlake. 1990. abaA controls phialide differentiation in Aspergillus nidulans. Plant Cell 2: 731-739.

Thireos, G., M.D. Penn, and H. Greer. 1984. 5' Untranslated sequences are required for the translational control of a yeast regulatory gene. Proc. Nat1. Acad. Sci. 81: 5096-5100.

Timberlake, W.E. 1980. Developmental gene regulation in Aspergillus nidulans. Dev. Biol. 78: 497-510.

- 1990. Molecular genetics of Aspergillus development. Annu. Rev. Genet. 24: 5-36.

Tzamarias, D., I. Roussou, and G. Thieros. 1989. Coupling of GCN4 mRNA translational activation with decreased rates of polypeptide chain initiation. Cell 57: 947-954.

Werner, M., A. Feller, F. Messenguy, and A. Pierard. 1987. The leader peptide of yeast gene CPA1 is essential for the translational repression of its expression. Cell 49: 805-813.

Yager, L.N., M.B. Kurtz, and S.P. Champe. 1982. Temperatureshift analysis of conidial development in Aspergillus nidulans. Dev. Biol. 93: 92-103.

Yelton, M.M., J.E. Hamer, and W.E. Timberlake. 1984. Transformation of Aspergillus nidulans by using a $\operatorname{trp} C$ plasmid. Proc. Natl. Acad. Sci. 81: 1470-1474.

Zimmermann, C.R. 1986. "A molecular genetic analysis of developmental gene regulation in Aspergillus nidulans." Ph.D. thesis, University of California, Davis, CA. 




\section{StuA is required for cell pattern formation in Aspergillus.}

$\mathrm{K}$ Y Miller, J Wu and B L Miller

Genes Dev. 1992, 6:

Access the most recent version at doi:10.1101/gad.6.9.1770 $\begin{array}{ll}\text { References } & \begin{array}{l}\text { This article cites } 50 \text { articles, } 19 \text { of which can be accessed free at: } \\ \text { http://genesdev.cshlp.org/content/6/9/1770.full.html\#ref-list-1 }\end{array}\end{array}$

License

Email Alerting

Receive free email alerts when new articles cite this article - sign up in the box at the top Service right corner of the article or click here.

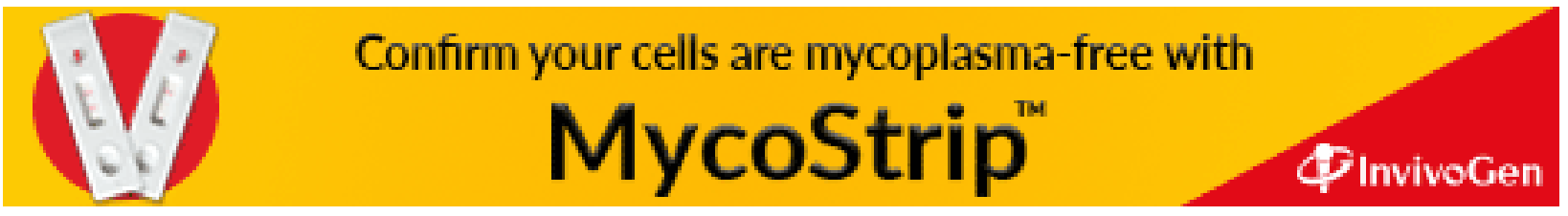

